\title{
Chronicle of an injured mugger crocodile (Crocodylus palustris) surviving in the Vishwamitri River, India
}

\author{
RAJU VYAS
}

Shashwat Apartment, 23 Anandnagar Society, BPC Road, Alkapuri, Vadodara 390007, Gujarat, India Author e-mail: razoovyas@hotmail.com

$T^{n}$ he mugger crocodile (Crocodylus palustris) is an apex predator in fresh water eco-systems with legal protection under the Indian Wildlife (Protection) Act, 1972as a 'Schedule I' species. It is also considered 'Vulnerable' by IUCN criteria.

By the early 1960s in India, the species was depleted on account of illegal hunting, fishing and habitat loss (Whitaker \& Andrews, 2003). However, mugger populations are now flourishing due to legal protection and successful conservation programmes (Singh, 1999). Consequently, at times there are conflicts between crocodiles and humans (Vijayakumar et al., 1999; Jayson, 2002; Whitaker, 2007; Vyas \& Stevenson, 2017). The River Vishwamitri contains a substantial population of muggers, the last count shows the presence of 250 various sized specimens inhabiting a $25 \mathrm{~km}$ long stretch of this river in the largely human-dominated urban landscape of Vadodara city (Vyas, 2018). Every year a small number of muggers venture into human habitats and create panic amongst local people. This has inspired wildlife enthusiasts, to run 'save mugger' campaigns, an endeavour also supported by nongovernmental organisations and the state Forest Department. Collectively, these agencies rescue and release troublesome muggers elsewhere in the same river system (Vyas, 2012). Between 2001 and 2010, many such rescued muggers were marked before release by caudal scute-clipping. This is a universally accepted method of individual identification, performed by clipping vertical caudal scutes in various combinations, with each combination designating a unique code number (Bustard \& Choudhury, 1981).

On 25th July 2005 , a badly injured mugger, measuring $1.8 \mathrm{~m}$ total length, was rescued from a small pool at Fokal, Zumkal, Vadodara $\left(22^{\circ} 25^{\prime} 55.47^{\prime \prime} \mathrm{N} ; 73^{\circ} 12^{\prime} 19.14^{\prime \prime} \mathrm{E}\right)$. The animal had lost the anterior part of the upper jaw (Fig.1), probably as a result of mutilation by local people using an axelike weapon. This injured animal was tail clipped '247' by the Gujarat Society for Prevention of Cruelty to Animals, before release upstream of the Vishwamitri River in the waters of Lake Ajwa ( $\left.22^{\circ} 22^{\prime} 47.11^{\prime \prime} \mathrm{N} ; 73^{\circ} 23^{\prime} 2.07^{\prime \prime} \mathrm{E}\right)$; a man-made water body of $15 \mathrm{~km}^{2}$. Considering the severity of its wound it would not have been expected to survive due to infection, starvation, or lack of defence against other crocodiles. The act of releasing a crocodile with such potentially fatal injuries, without any expert advice or veterinary consultation, was widely criticised by local conservationists and wildlife enthusiasts.

Eleven years later, in April 2016, a half-jawed mugger

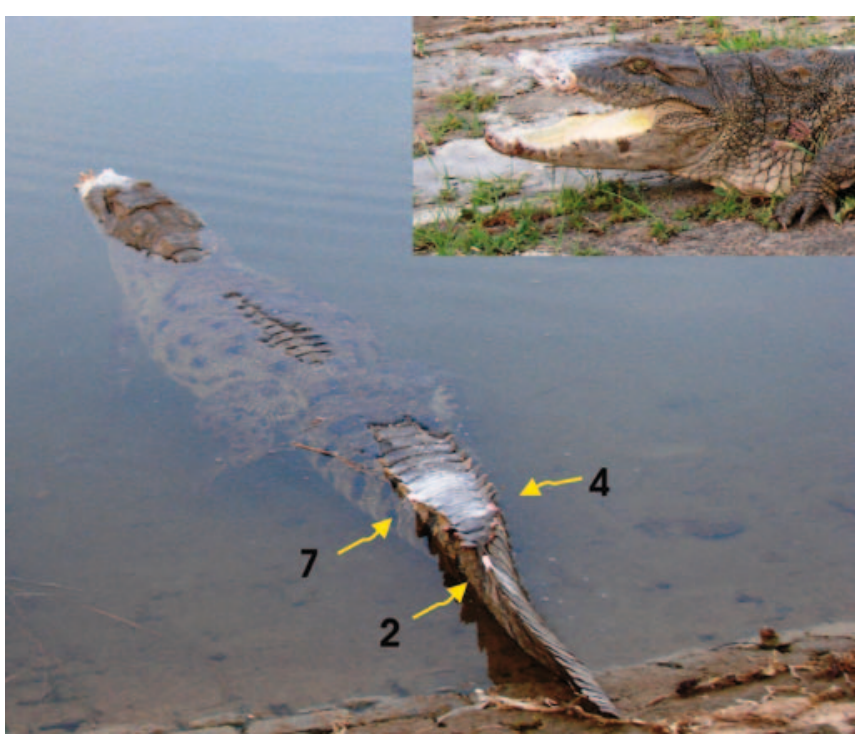

Figure 1. Rescued C. palustris No. 247 marked by clipping tail scutes (vertical single row 2 nd scute, 4 th left and 7 th right of double vertical row) before release, at Ajwa Lake, Vadodara. Inset at top, a lateral view of head showing missing one third of upper jaw.

was sighted (Fig. 2), along with 12 other muggers near the Vishwamitri river banks at Kirti Mandir, Vadodara $\left(22^{\circ}\right.$ $\left.18^{\prime} 33.16^{\prime \prime} \mathrm{N} ; 73^{\circ} 11^{\prime} 23.31^{\prime \prime} \mathrm{E}\right), 22 \mathrm{~km}$ (as the crow flies) west of Lake Ajwa. It was identified as mugger No. 247 with a completely healed upper jaw but without the nostril valve; the teeth in its lower jaw had grown large, and the animal seemed to be faring well. This sighting raised questions about how this mugger managed to travel so far after release and how it had survived the severe injury. It seems possible that the mugger had been washed out from the upstream area during the floods of 2014, when the water level of the river Vishwamitri reached $10.2 \mathrm{~m}$ leaving the entire area flooded. In the same year, about 48 various sized muggers were rescued from urban areas of Vadodara city (Vyas, 2018).

Another similarly injured mugger, with a missing upper half jaw, has been recorded (Vyas, 2014). That injury was caused by a territorial fight with a dominant, larger, residential male mugger. Subsequently, the victim survived a decade in captivity at the Sayajibaug Zoo, Vadodara. All crocodiles appear to have remarkably robust natural immune systems so that animals with extensive wounds apparently rarely succumbed to infection (Finger \& Isberg, 2012). This fact indicates the 


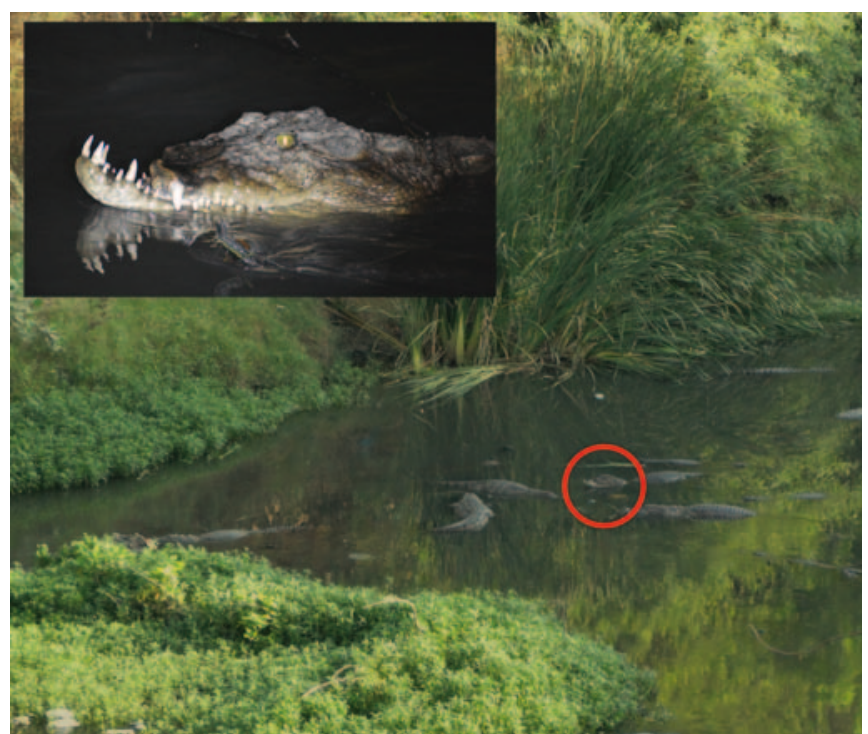

Figure 2. Mugger (C. palustris) No. 247 roaming along with a dozen of other large muggers in the waters of Vishwamitri near Kirti Mandir, Vadodara

importance of studies on the crocodilian immune system and wound healing. Happily, since its first reappearance in April 2016, No. 247 has continued to resurface to the present day.

\section{ACKNOWLEDGEMENTS}

I am thankful to all staff members of NGOs and government organisations for help in various aspects of information and study. Special thanks to Lt. Snehal Bhavsar, Rajesh Bhavsar, Kartik Upadhyay and Krupal Patel for providing photographs, sharing information and accompanying me during the fieldwork. Finally, I am grateful to Khushboo Vyas for reviewing the draft manuscript.

\section{REFERENCES}

Bustard, H. R. \& Choudhury, B. C.(1981). Marking of crocodiles for release back into the wild for subsequent identification. Indian Forester 107: 477-85.

Finger, J. W. Jr. \& Isberg, S. R. (2012). A review of innate immune functions in crocodilians. CAB Review 7:1-11. doi: 10.1079/ PAVSNNR20127067

Jayson, E. A. (2002). Human-Crocodile conflict in Neyyar Wildlife Sanctuary, Thiruananthapuram, Kerala. Reptile Rap 4: 1-2.

Singh, L. A. K. (1999). Significance and achievements of the Indian Crocodile Conservation Project. ENVIS (Wildlife \& Protected Area) 2: 10-16.

Vijayakumar, V., Vyas R. \& Choudhury, B. C.(1999). Status of mugger and its conservation problems in Gujarat. ENVIS (Wildlife \& Protected Area) 2: 69-76.

Vyas, R. (2012). Current status of Marsh Crocodiles Crocodylus palustris (Reptilia: Crocodylidae)in Vishwamitri River, Vadodara City, Gujarat, India. Journal of Threatened Taxa 4: 3333-3341.

Vyas, R. (2014). Note on a seriously injured male mugger crocodile (Crocodylus palustris) surviving in captivity. CSG Newsletter 33: 8-10.

Vyas, R. (2018). Result of the 2015 mugger crocodile (Crocodylus palustris) count at Vadodara, Gujarat, India. IRCF Reptiles \& Amphibia 25: 20-25.

Vyas, R. \& C. Stevenson. (2017). Review and analysis of human and Mugger Crocodile conflict in Gujarat, India from 1960 to 2013. Journal of Threatened Taxa: 11016-11024. http:// dofi.org/10.11609/joft.3790.9.12.11016-11024.

Whitaker, N. (2007). Survey on Human Crocodile Conflict in India, Maharashtra State, December 2007, Madras Crocodile Bank Trust. 25 pp.

Whitaker, R. \& Andrews, H. V. (2003). Crocodile conservation, Western Asia region: An update. Journal of Bombay Natural History Society 100: 432-445.

Accepted: 31 July 2019 